\title{
HPMC K15M and Carbopol 940 mediated fabrication of ondansetron hydrochloride intranasal mucoadhesive microspheres
}

\author{
Poonam Dhawale ${ }^{1}$, Nilesh M. Mahajan ${ }^{1}$, Debarshi Kar Mahapatra ${ }^{2}$, Ujwala N. Mahajan ${ }^{3}$, Purushottam S. Gangane ${ }^{*}$ \\ ${ }^{1}$ Department of Pharmaceutics, Dadasaheb Balpande College of Pharmacy, Nagpur 440037, Maharashtra, India. \\ ${ }^{2}$ Department of Pharmaceutical Chemistry, Dadasaheb Balpande College of Pharmacy, Nagpur 440037, Maharashtra, India. \\ ${ }^{3}$ Department of Quality Assurance, Dadasaheb Balpande College of Pharmacy, Nagpur 440037, Maharashtra, India.
}

\section{ARTICLE INFO \\ Article history: \\ Received on: 13/05/2018 \\ Accepted on: 22/06/2018 \\ Available online: $31 / 08 / 2018$}

\section{Key words:}

Nasal drug delivery,

Mucoadhesive,

Microsphere, Solvent

evaporation technique,

Ondansetron hydrochloride,

Bioavailability.

\begin{abstract}
The purpose of the present research was the design, development, and evaluation of ondansetron hydrochloride loaded polymeric mucoadhesive microspheres for intranasal delivery to avoid first-pass metabolism phenomenon in the liver and to improve its residence time. The microspheres were fabricated by a solvent evaporation method using carbopol 940 and HPMC K15M as a mucoadhesive polymer along with ethyl cellulose as a film-forming polymer. The intention of the current study was to comprehensively examine the influence of formulation components and the probable process variables such as a polymer to polymer ratio and stirring rate on the characteristics of the microspheres prepared. The microspheres were characterized for drug-polymer interactions, entrapment efficiency, drug loading, swelling property, particle size analysis, thermal behavior, morphological, in-vitro mucoadhesion, ex-vivo drug permeation, in-vitro drug release, histopathology, and release kinetic studies. The research will open new avenues for increasing the bioavailability of ondansetron hydrochloride in the future.
\end{abstract}

\section{INTRODUCTION}

Ondansetron hydrochloride $(\mathrm{OH})$ is a serotonin type $3\left(5-\mathrm{HT}_{3}\right)$ receptor antagonist with competitive in nature. It is an effectual drug for the management of nausea and vomiting caused during the chemotherapy, radiotherapy, and postoperative vomiting. $\mathrm{OH}$ has very low oral bioavailability $(\sim 60 \%)$ due to high liver first-pass metabolism. It is not possible to administer $\mathrm{OH}$ orally to patients suffering from severe vomiting, the administration of a drug through the nasal route could be a better option to avoid symptoms of nausea and vomiting linked with the therapy. Furthermore, $\mathrm{OH}$ has comparatively short elimination half-life $(\sim 3 \mathrm{hr})$, hence, an extended drug release is seldom required (Mahapatra and Bharti, 2018).

\footnotetext{
${ }^{*}$ Corresponding Author

Purushottam S. Gangane, PhD, Assistant Professor, Department of

Pharmaceutics, Dadasaheb Balpande College of Pharmacy, Nagpur 440037, Maharashtra, India.

E-mail:p.gangane@gmail.com
}

After parenteral administration of the drug, application in the nasal cavity remained the most viable alternative for enhancing the bioavailability of drug (Mahapatra and Bharti, 2017). Intranasal solutions, powders, suspensions, and snuffs are cleared swiftly from the nasal cavity and drugs do not absorb properly from these types of dosage forms (Nanjwade et al., 2011). The nasal mucoadhesive microspheres formulation provides extended drug release which remains an attractive way to increase to enhance the bioavailability of $\mathrm{OH}$. The primary rationale behind the formulation of nasal mucoadhesive microspheres is to increase drug absorption by providing more intimate contact between the drug and the mucosal membrane. Mucoadhesive microspheres provide a better chance for absorption by converting into a viscous gel after swelling and absorbing water from nasal mucus, as a result of this the epithelial cells are dehydrated and cause the opening of tight junction (Jain et al., 2009). The nasal route of administration is one of the most encouraging routes for the drug administration over the years owing to several pharmacotherapeutic advantages such as a highly vascularised 
epithelial layer which offer a comparatively outsized surface area for absorption and better avoiding of first-pass hepatic metabolism that cumulatively proffer high bioavailability (Behl et al., 1998). Formulating microspheres will safeguard the therapeutic content from unnecessary enzymatic metabolism and will, therefore, prolong the drug release. In addition, the drug administered from nasal mucosa by microsphere is directly absorbed into the systemic circulation (Pardeshi et al., 2012).

The bioadhesive polymers present in the mucoadhesive drug delivery systems, on hydration, becomes adhesive in nature and therefore finds perspectives for targeting the $\operatorname{drug}(\mathrm{s})$ to specific body locations to extend the therapeutic effect (Mahajan et al., 2012). Nasal mucociliary clearance (MCC) is a defensive mechanism of the human body that reduces the residence time of the drug administered in the nasal cavity and facilitates the absorption of drug (Mahapatra and Bharti, 2016). The cellulose derivatives such as HPMC $\mathrm{K} 15 \mathrm{M}$ can noticeably extend the residence time of the drugs at the absorption site owing to their attractive mucoadhesion attributes. Polyacrylates such as carbopol 940 are proficient enough to attach to the nasal mucosal region and subsequently give the potential of extending the drug's residence time at the region of drug absorption since it provides contact between the drug formulation and the absorption membrane surface (Pagar et al., 2013). Therefore, to increase the bioavailability of poorly absorbed drugs in form of a mucoadhesive polymer containing microspheres from nasal mucosa either nasal permeability can be increased by decreasing the MCC and simultaneously, the contact time of the drug with the nasal mucosa can be an increase (Prasanth et al., 2011).

In the present research, solvent evaporation technique, which is one of the most common and suitable methods to fabricate the polymeric microspheres, have been utilized to facilitate sustained release of $\mathrm{OH}$ employing polymer combinations of
HPMC K15M and carbopol 940, along with film-forming ethyl cellulose as the film former.

\section{MATERIALS AND METHOD}

\section{Materials}

The sample of ondansetron hydrochloride was received as a generous gift from Maxwell Life Science Private Limited, Mumbai. Carbopol 940 was procured from HiMedia Lab Pvt. Ltd., Mumbai. HPMC K15M and ethyl cellulose were acquired from Colorcon Limited, Goa. All other chemical reagents employed during the experiment were of analytical grade and procured from registered vendors.

\section{Preparation of microspheres by a solvent evaporation technique}

By emulsion solvent evaporation method, the $\mathrm{OH}$ loaded mucoadhesive microspheres were fabricated by utilizing two different mucoadhesive polymers; HPMC K15M and Carbopol $940(\mathrm{Cb})$. The ethyl cellulose (EC) polymer was employed for controlling the release of the drug (Table 1). EC and HPMC K15M (P-series)/Cb (N-series) were dissolved in $50 \mathrm{~mL}$ of ethanol by means of a magnetic stirrer. Subsequently, the weighed amount of drug was added to the EC-Cb solution during continuous stirring to produce a uniform dispersion. The dispersion was quickly injected into $200 \mathrm{~mL}$ of light liquid paraffin (containing $2.5 \%$ $\mathrm{v} / \mathrm{v}$ of Span 80 ) using a $5 \mathrm{~mL}$ syringe. Initially, the stirring speed was kept higher for the duration of $1 \mathrm{~min}$ to formulate the w/o emulsion. Thereafter, the stirring speed was reduced significantly and maintained for $2 \mathrm{hr}$ at room temperature until ethanol was completely evaporated to produce the microspheres. The microspheres were filtered through Whatman filter paper, washed thoroughly for 2-3 times with n-hexane, and further dried at room temperature for $24 \mathrm{hr}$.

Table 1: Formulation attributes of ondansetron $\mathrm{HCl}$ mucoadhesive microspheres.

\begin{tabular}{|c|c|c|c|c|c|c|}
\hline Mucoadhesive polymer & Formulation Code & Drug (mg) & Mucoadhesive polymer (mg) & Film forming polymer (mg) & Polymer ratio (w/w) & Stirring speed (rpm) \\
\hline \multirow{4}{*}{ Carbopol 940} & N1 & 500 & 500 & 1500 & $1: 3$ & 1500 \\
\hline & $\mathrm{N} 2$ & 500 & 500 & 1500 & $1: 3$ & 2000 \\
\hline & N3 & 500 & 500 & 2500 & $1: 5$ & 1500 \\
\hline & N4 & 500 & 500 & 2500 & $1: 5$ & 2000 \\
\hline \multirow{4}{*}{ HPMC K15M } & P1 & 500 & 500 & 1500 & $1: 3$ & 1500 \\
\hline & P2 & 500 & 500 & 1500 & $1: 3$ & 2000 \\
\hline & P3 & 500 & 500 & 2500 & $1: 5$ & 1500 \\
\hline & P4 & 500 & 500 & 2500 & $1: 5$ & 2000 \\
\hline
\end{tabular}

\section{Characterization of microspheres}

\section{Production yield (\%)}

The yield of the produced formulations was estimated as per the weight $\%$ of the final product after drying, with contrast to the initial total amount of the drug and polymer employed in the fabrication of microspheres. The equation (1) describes the method for calculating production (Abbas et al., 2014).
Drug loading (\%) and entrapment efficiency (\%)

Production yield \%

$$
=\frac{\text { Practical mass }(\text { microspheres })}{\text { Theoretical mass (polymer+drug) }} \times 100
$$

For determining drug loading and entrapment efficiency, weighed the quantity of microspheres were dissolved 
in methanol and kept during the night on a mechanical shaker to extract the complete entrapped drug. The obtained solution was filtered through Whatman filter paper and analyzed by using a UV spectrophotometer at $248 \mathrm{~nm}$. The drug loading (DL) and entrapment efficiency (EE) were determined as per equations (2) and (3), respectively (Pilicheva et al., 2013).

$$
\mathrm{DL}(\%)=\frac{\begin{array}{c}
\text { Actual amount of drug loaded } \\
\text { in microspheres }
\end{array}}{\text { Weighed quantity of microspheres }} \times 100
$$

$$
\mathrm{EE}(\%)=\frac{\begin{array}{c}
\text { Actual amount of drug entrapped } \\
\text { in microspheres }
\end{array}}{\text { Amount of drug added }} \times 100
$$

\section{Particle size analysis}

The particle size was determined using a microscopic image analysis technique, where motic digital microscope set with a 1/399 CCD camera imaging accessory equipped with computercontrolled image analysis software (Motic images plus 2) was employed. For the investigation, the microspheres were initially dispersed over the microscope slide and the scanning of the microscopic field was done by a video camera. By using software, the images of the scanned field were recorded and analyzed (Swamy and Abbas, 2011).

\section{Degree of swelling}

The swelling attribute of the microspheres was estimated by primarily swelling the material in phosphate buffer solution $(\mathrm{pH}$ 6.6) where a precise weighed quantity of microspheres was placed on a Millipore filter (NY 11, $0.22 \mu \mathrm{m}$ ) using a Franz diffusion cell with phosphate buffer ( $\mathrm{pH}$ 6.6) and remain for the duration of 3.5 min. The degree of swelling in physiological media was calculated using the following formula given in equation (4) (Shahi et al., 2014).

$$
\alpha=\frac{(\mathrm{Ws}-\mathrm{Wo})}{\mathrm{Ws}}
$$

where, $\alpha=$ degree of swelling; Wo = initial weight of microspheres, and $\mathrm{Ws}=$ weight of microspheres after swelling.

\section{Drug-interaction studies}

The possibility of any interaction of ondansetron hydrochloride with the employed polymers; HPMC K15M, carbopol 940, and ethyl cellulose was estimated by Fourier-transformed infrared (FT-IR) spectroscopy (Shimadzu ${ }^{\circledR}$ IRAffinity-1). To inspect the compatibilities in the formulation and to ensure the fitness of polymer in the preparation of microsphere, samples of drug loaded microspheres were prepared into $\mathrm{KBr}$ disks and scanned in the range from 4000-400 $\mathrm{cm}^{-1}$ (Umaredkar et al., 2018).

\section{Thermal behavior study}

The physical state of $\mathrm{OH}$ and thermal behavior of drug loaded microsphere formulation were studied by differential scanning calorimeter (DSC) thermogram technique (Mettler Toledo). The sample was heated with alpha alumina powder in the range of $30-300^{\circ} \mathrm{C}$ at a scanning rate of $10^{\circ} \mathrm{C} / \mathrm{min}$ in a platinum crucible under the atmosphere of nitrogen $(150 \mathrm{~mL} / \mathrm{min})$, keeping indium as a standard for temperature calibrations (Godbole et al., 2017).

\section{Morphological studies}

The scanning electron microscopy (SEM) (JEOL, JSM-5610 LV, Japan) was utilized for studying the external topological and morphology of the prepared $\mathrm{OH}$ microspheres. The microspheres were mounted on metal stubs with double-sided tape stuck to an aluminum stub. The stub containing the coated samples was positioned in the SEM at the acceleration voltage of $30 \mathrm{kV}$. The fabricated samples were subsequently scanned at random and the photomicrographs were examined at $\times 55$ and $\times 60$ magnifications (Dangre et al., 2016).

\section{In-vitro mucoadhesion study}

The mucoadhesion studies were performed to make certain that prepared formulation will adhere to the mucosa for a long-lasting duration at the absorption location. The mucoadhesion potential of the fabricated microspheres was evaluated by initially mounting a small portion of the goat nasal mucosa, obtained from sacrificed goat within $1 \mathrm{hr}$ on a glass slide and sprinkling exactly measured microspheres on the mucosal surface. The mucosa mounted glass slide was desiccated for 15 min so that the polymer interacts strongly with the mucosal membrane. In the end, the slide was placed inside the cell supplying phosphate buffer of $\mathrm{pH} 6.6$ at the rate of $5 \mathrm{~mL} / \mathrm{min}$ and maintained at $37 \pm 0.5^{\circ} \mathrm{C}$. The cell was attached systematically to the outer assembly at an angle of $45^{\circ}$. The perfusate was collected after $1 \mathrm{hr}$ and the amount of the drug present was estimated spectrophotometrically at $248 \mathrm{~nm}$. The concentration of microspheres equivalent to the amount of drug in perfusate was calculated. The amount of adhering microspheres was calculated from the disparity between the number of microspheres applied and microspheres flowed. The ratio of the adhered microspheres was determined as a percentage mucoadhesion as per the given formula (Kulkarni et al., 2016).

$$
\% \text { Mucoadhesion }=(\mathrm{Wa}-\mathrm{Wo}) \times 100 / \mathrm{Wa},
$$

where $\mathrm{Wa}=$ weight of microspheres applied; Wo $=$ weight of microspheres leached out.

\section{In-vitro drug release study}

The in vitro drug release rate of microspheres was performed using a USP 33 dissolution test apparatus II (Paddle type) at $\mathrm{pH} 6.6$ phosphate buffer using dissolution medium of 900 $\mathrm{mL}$ at $37 \pm 0.5^{\circ} \mathrm{C}$, with rotor speed $50 \mathrm{rpm}$. The accurately weighed quantity of microsphere equivalent to $15 \mathrm{mg}$ of the drug was tied in a muslin cloth and the drug release study was performed by withdrawing $1 \mathrm{~mL}$ sample at programmed time intervals. The media was restored with fresh medium to maintain the sink condition. The samples were filtered through Whatman filter paper and assayed after suitable dilution strength by a UV spectrophotometer (Shimadzu ${ }^{\circledR}$ UV-1800, Japan) at $248 \mathrm{~nm}$. The excipients employed in the formulation do not interfere with the assay. The release study was conducted in triplicate (Sonkusre et al., 2016). 


\section{Ex-vivo permeation study}

The ex-vivo permeation study was performed employing Franz's diffusion cell on a goat nasal mucosa, collected from the slaughterhouse within $1 \mathrm{hr}$ of sacrifice. The sample corresponding to $15 \mathrm{mg}$ of the drug was applied into the donor compartment containing $3 \mathrm{~mL}$ of simulated nasal fluid (aqueous solution containing $8.77 \mathrm{mg} / \mathrm{mL}$ of $\mathrm{NaCl}, 2.98 \mathrm{mg} / \mathrm{mL}$ of $\mathrm{KCl}$, and 0.59 $\mathrm{mg} / \mathrm{mL}$ of $\mathrm{CaCl}_{2}$ per liter). The receiver compartment comprised of a phosphate buffer solution ( $\mathrm{pH}$ 6.6) which is the approximate $\mathrm{pH}$ range corresponding to the nasal cavity. The donor chamber was put in such a technique that it remained in contact with the diffusion medium present in the receptor chamber. The temperature was sustained correspondent at $37 \pm 0.5^{\circ} \mathrm{C}$ with the aid of a flowing water bath. The samples were intermittently taken off from the receptor compartment and sink condition was maintained by replacing with the identical quantity of fresh buffer solution. The content was analyzed using a UV spectrophotometer (Shimadzu ${ }^{\circledR}$ UV-1800, Japan) at $248 \mathrm{~nm}$ (Taksande and Umekar, 2018).

\section{Histopathological study}

The histopathological studies were performed on a sheep nasal mucosa which was procured from the local abattoir within $1 \mathrm{hr}$ of sacrifice. The mucosa was thoroughly cleaned with the isotonic saline solution $(0.9 \%)$. The $\mathrm{OH}$ microspheres were applied on the nasal mucosa, after the lapse of $1 \mathrm{hr}$, the nasal mucosa was set with $10 \%$ neutral carbonate buffered formalin solution and subsequently embedded in paraffin. The paraffin sections were cut on a glass slide and further stained with the eosin dye. The untreated mucosa directly fixed after the proper isolation at the slaughterhouse was selected as the control (Desai et al., 2011).

\section{Drug release kinetics}

The dissolution profiles of all the prepared formulation batches were fitted to a range of drug release mechanism(s) models like Korsmeyer-Peppas (drug releases till the polymer chains rearrange to equilibrium state), Higuchi (drug release from an insoluble matrix as the square root of time-dependent process), Hixson-Crowell (drug release from the systems due to modification in the surface area and the particle diameter), First order (drug release rate is concentration dependent), and Zeroorder (drug release rate is self-governing of its concentration) for determining the kinetics of drug release. The suitable model was selected based on a goodness-or fit test where correlation coefficient $\left(\mathrm{r}^{2}\right)$ and release exponent (n) were expressed for each model in correlation to the drug kinetics (Mahajan et al., 2017).

\section{RESULTS AND DISCUSSION}

The $\mathrm{OH}$ mucoadhesive microspheres prepared by solvent evaporation technique utilizing the polymers; HPMC K15M and carbopol 940 represented an effective way of formulating control release formulation. When the consequences of batches of both the $\mathrm{OH}$ mucoadhesive microsphere series for intra-nasal delivery were compared with the existing literature depicting the utilizing of various well-known polymers (pectin, gellan gum, chitosan, etc.) and techniques (spray-drying method, etc.); a sharp contrast in results were observed (Nanjwade et al., 2011; Jain et al., 2009; Kashikar et al., 2014; Shashi et al., 2011; Jain et al., 2012). The solvent evaporation technique employed for fabricating the $\mathrm{OH}$ mucoadhesive microspheres utilizing HPMC and $\mathrm{Cb}$ described an imperative method with high yield, better mucoadhesivity, higher drug loading with enhanced percentage entrapment, etc than the previous reports (Dandge and Dehghan, 2009; Mahajan et al., 2008).

Table 2: Evaluation parameters of ondansetron hydrochloride mucoadhesive microspheres.

\begin{tabular}{|c|c|c|c|c|c|c|}
\hline Formulation code & Production yield (\%) & $\begin{array}{l}\text { Drug loading } \\
\quad(\mu \mathrm{m} \pm \mathrm{SD})\end{array}$ & $\begin{array}{c}\text { Entrapment efficiency } \\
(\mu \mathrm{m} \pm \mathrm{SD})\end{array}$ & $\begin{array}{l}\text { Average particle size } \\
\qquad(\mu \mathrm{m} \pm \mathrm{SD})\end{array}$ & $\begin{array}{l}\text { Degree of swelling } \\
\quad(\mu \mathrm{m} \pm \mathrm{SD})\end{array}$ & $\begin{array}{c}\text { Mucoadhesion } \\
\quad(\mu \mathrm{m} \pm \mathrm{SD})\end{array}$ \\
\hline N1 & 84.64 & $17.84 \pm 0.36$ & $79.55 \pm 0.14$ & $25.22 \pm 1.64$ & $0.89 \pm 0.15$ & $99.56 \pm 1.04$ \\
\hline N2 & 89.24 & $14.34 \pm 0.54$ & $77.98 \pm 0.17$ & $15.54 \pm 0.94$ & $0.87 \pm 0.06$ & $98.12 \pm 0.61$ \\
\hline N3 & 81.40 & $13.90 \pm 0.42$ & $76.10 \pm 0.43$ & $30.98 \pm 1.54$ & $0.84 \pm 0.21$ & $96.23 \pm 1.27$ \\
\hline N4 & 87.45 & $13.96 \pm 0.46$ & $72.42 \pm 0.26$ & $18.72 \pm 1.52$ & $0.83 \pm 0.05$ & $97.89 \pm 0.66$ \\
\hline $\mathrm{P} 1$ & 95.12 & $15.49 \pm 0.89$ & $74.99 \pm 0.18$ & $23.68 \pm 0.96$ & $0.68 \pm 0.17$ & $96.56 \pm 2.12$ \\
\hline $\mathrm{P} 2$ & 98.12 & $10.41 \pm 1.37$ & $70.27 \pm 0.42$ & $13.87 \pm 0.86$ & $0.65 \pm 0.23$ & $94.45 \pm 1.44$ \\
\hline P3 & 97.60 & $9.43 \pm 0.53$ & $69.16 \pm 0.16$ & $31.20 \pm 1.16$ & $0.57 \pm 0.31$ & $93.75 \pm 0.77$ \\
\hline $\mathrm{P} 4$ & 98.42 & $10.12 \pm 0.37$ & $64.45 \pm 0.18$ & $15.25 \pm 1.75$ & $0.54 \pm 0.16$ & $91.69 \pm 0.54$ \\
\hline
\end{tabular}

* values expressed as mean $\pm \mathrm{SD}, \mathrm{n}=3$.

\section{Drug-interaction studies}

The FT-IR spectra of pure OH drug (Figure 1a), carbopol 940 (Figure 1b), HPMC K15M (Figure 1c), ethyl cellulose (Figure 1d), physical mixture (Figure 1e), and mucoadhesive microspheres (Figure 1f) were recorded which revealed no possible interactions between the drug and mucoadhesive polymers. There was no substantial modification in the positions of characteristic absorption bands and bonds of diverse functional groups present in the drug, indicating no such drug-excipients interactions. In the physical mixture and optimized formulation N1, the drug remained in the pure, unchanged, and non-interactive state. The results stated that $\mathrm{OH}$ was compatible with carbopol 940, HPMC $\mathrm{K} 15 \mathrm{M}$, and ethyl cellulose.

Production yield (\%)

The production yield of microspheres was found to be in the range of $81.4-98.42 \%$ (Table 2). It was found that the 
production yield of the mucoadhesive microspheres prepared from HPMC K15M was higher than Carbopol 940. The plausible cause following the difference in yield may be due to the high viscosity offered by the carbopol solution which may decrease its syringability resulting in the needle orifice blockade and leading to drug-polymer solution wastage, which eventually leads to decrease in the production yields. Another probable reason for that reduced yield may be the sticking and agglomeration of the polymeric contents to the wall of the beaker and the blades of the stirrer during the microsphere formation.
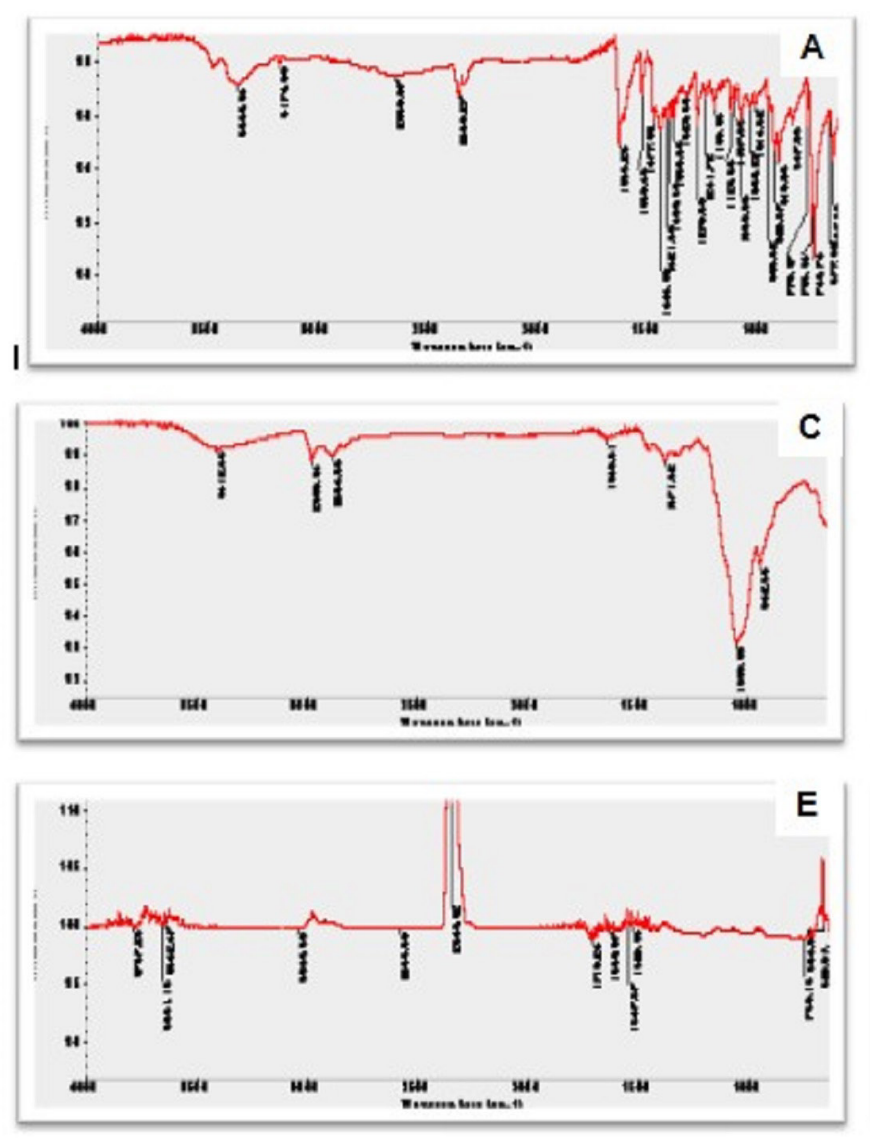

Fig. 1: FT-IR spectra of (A) ondansetron hydrochloride; (B) carbopol 940; (C) microspheres.

\section{Particle size analysis}

The average size of the fabricated mucoadhesive microspheres were in the range of $15-31 \mu \mathrm{m}$ which is an optimized size for nasal administration (Figure 2c). The rate of stirring had a key influence over the particle size. It was detected that with the increase in the stirring rate, the particle size decreases abruptly, irrelevant of the mucoadhesive polymer concentration (Table 2).

\section{Swelling property}

The swelling index of the mucoadhesive microsphere ranged from 0.54-0.89 (Figure 2d). In the study, carbopol microspheres exhibited a higher degree of swelling than the HPMC $\mathrm{K} 15 \mathrm{M}$ microspheres which may be due to the higher molecular

\section{Drug loading (\%) and entrapment efficiency (\%)}

The entrapment efficiency and drug content of the formulated $\mathrm{OH}$ microspheres were found to be in the range of 64.45 $79.55 \%$ and $9.4-17.84 \%$, respectively (Table 2 ). The N1 batch has the highest drug loading (Figure 2a) and entrapment efficiency (Figure $2 b)$ than other batches. It was scrutinized that with the increase in the concentration of mucoadhesive polymer, the entrapment efficiency increases simultaneously at higher and lower levels of stirring rate (Figure 2b). Though, it was distinguished that carbopol 940 had higher influence over entrapment efficiency than HPMC K15, owing to the higher molecular weight of carbopol than the HPMC which promotes the formation of more intact matrix network.
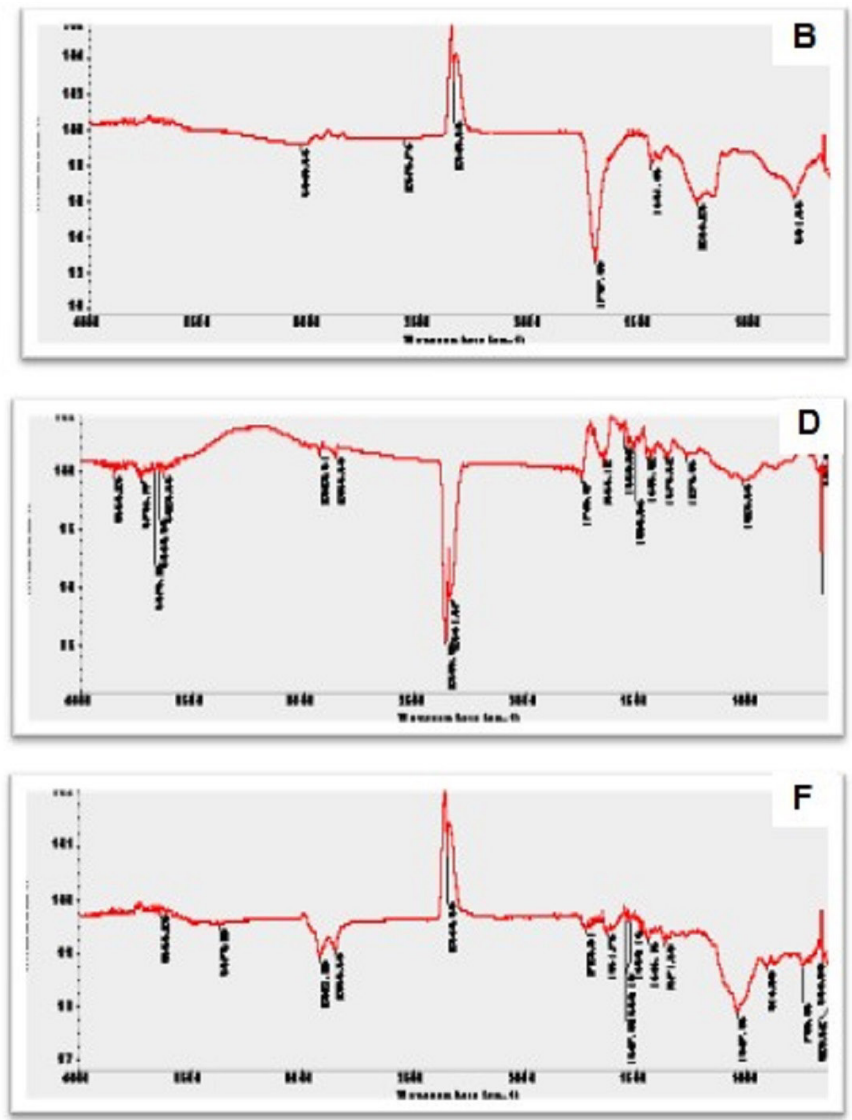

C) HPMC K15M; (D) ethyl cellulose; (E) physical mixture; and (F) mucoadhesive weight of the former polymer. However, a clear-cut conclusion was not produced. With the increase in the concentration of mucoadhesive polymer, a slight increase in swelling was observed. Similarly, a minor decline in the swelling attributes was observed at the lesser mucoadhesive polymer concentration which perhaps because of the higher level of ethyl cellulose, the film forming polymer in the formulations that allows slighter diffusion of water within the polymeric matrix (Table 2).

\section{In-vitro mucoadhesive studies}

The study revealed that the mucoadhesive microspheres sufficiently stick on the nasal mucosa (Table 2). The ratio of the adhered microspheres was expressed as \% mucoadhesion. 
From all batches, the total percentage of the microspheres attached to the nasal mucosa was ranged from about 91.6999.56\% (Figure 2e). The carbopol microspheres presented higher mucoadhesion attributes on account of the higher molecular weight of carbopol 940 than HPMC K15. Another reason was HPMC has low hydrogen-bonding capability with the mucus membrane due to its non-ionic nature, and thus exhibit lower mucoadhesivity.
It is also being known that the hydrophilic polymers have the characteristic to adhere with the mucosal surfaces, as a result of their ability to attract water molecules from the mucus gel layer (Patil et al., 2016). The studies also advocated that mucoadhesion increases with the enhancement of the mucoadhesive polymer concentration.
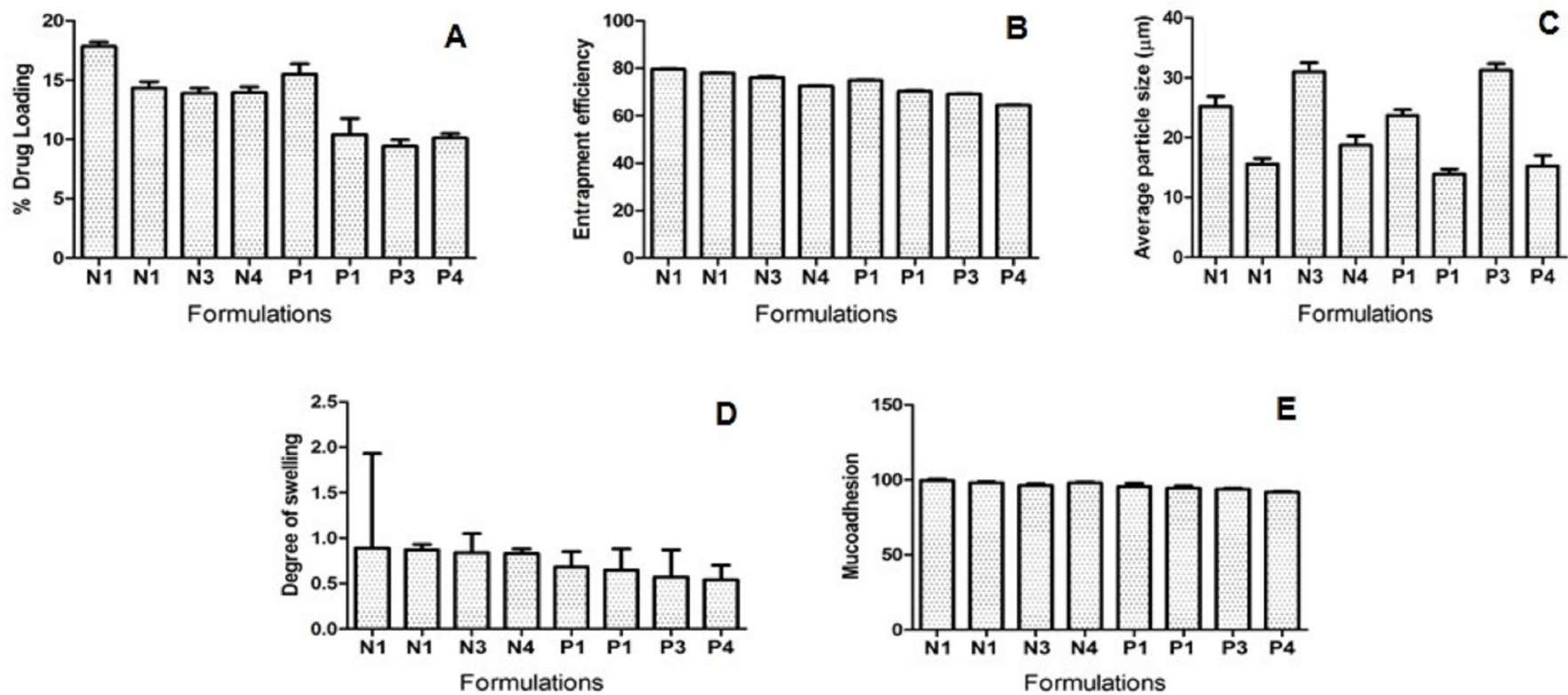

Fig. 2: Characterization of mucoadhesive microspheres: (A) \% drug loading study; (B) drug entrapment efficiency study; (C) particle size study; (D) in-vitro swelling study; (E) in -vitro mucoadhesion study.
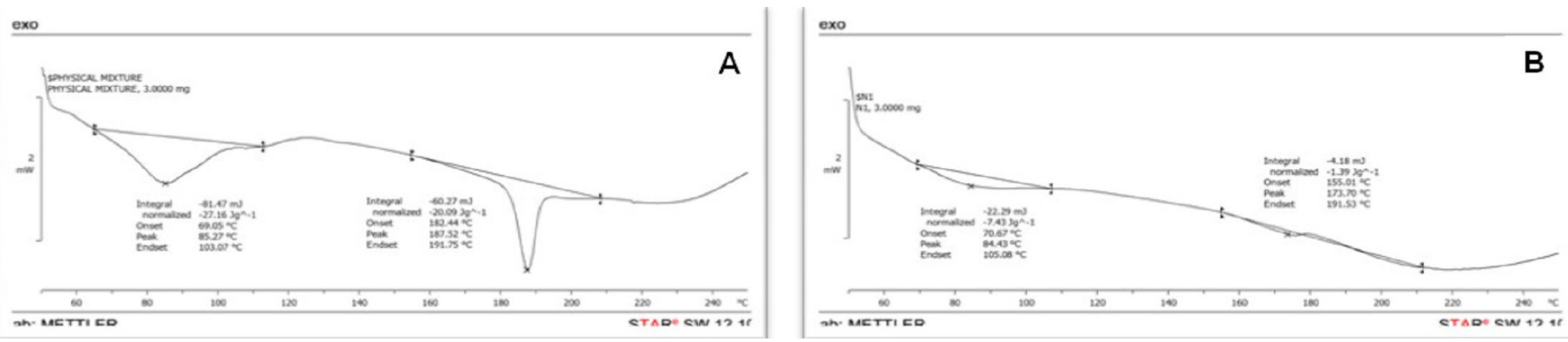

Fig. 3: Differential scanning calorimetric (DSC) thermogram: (A) physical mixture; (B) formulation N1.

\section{Thermal behavior studies}

The drug $\mathrm{OH}$ exhibited sharp endothermic peak at $187.52^{\circ} \mathrm{C}$ which matches exactly with its melting point. The sharp peak further confirmed the crystalline nature of the drug. The physical mixture containing the drug and polymers; HPMC $\mathrm{K} 15$, carbopol 940, and EC demonstrated broad endothermic peak and a sharp crystalline peak (Figure 3a) at $85.27^{\circ} \mathrm{C}$ over the entire scanning range of $30-300^{\circ} \mathrm{C}$ which demonstrated the presence of crystalline drug in the presence of polymers, however, the drug remains in the crystalline form and not amorphous transformation was seen. In the optimized formulation N1, no sharp peaks were observed (Figure $3 b$ ) and a marked difference from the physical mixture was observed (endothermic peak shifted to lower temperature) which suggested the swift transformation into the amorphous nature. Amorphous form is a high disorder state which facilitates the particles to distribute and remain in a highly dissolved state and the entire molten drug mix uniformly in the polymeric core (Dangre et al., 2016).

\section{Morphological studies}

The optimized formulation N1 was investigated by SEM for studying the morphology and surface characteristics of prepared mucoadhesive microspheres. The photomicrograph of the microspheres illustrated that the particles were well separated with a spherical shape having attached drug particles (Figure 4a). This suggested that the entire drug was found uniformly over the surface of the separated microstructures. The deep crevices 
and pinholes were observed, which may be due to the air bubble bursting during the drying process (Figure 4b).

\section{In-vitro drug release study}

The drug release profile of $\mathrm{OH}$ from various batches of carbopol 940 and HPMC K15M microspheres at $\mathrm{pH} 6.6$ phosphate buffer demonstrated significant drug release in the range of $70.5-81.5 \%$. The selected optimized batch of formulation $\mathrm{N} 1$ had the highest cumulative release $81.50 \%$ as compared to other formulations (Figure 5a). The ratio of polymeric content, mucoadhesive polymers content, film-forming polymer (EC), particle size, and formulation technique had a critical influence on drug release. The optimized formulation N1 expressed best drug release attribute due to the lowest concentration of film former (EC) and mucoadhesive polymers content which promotes low entrapment of drug in the polymeric matrix and facilitates higher release. In contrast, HPMC based formulations exhibited better control release and endorse low drug release. The reason may be that on becoming a contact of the polymer with the aqueous media, it forms a concentrated and thick gel which promotes more controlled drug delivery (Patil et al., 2016).
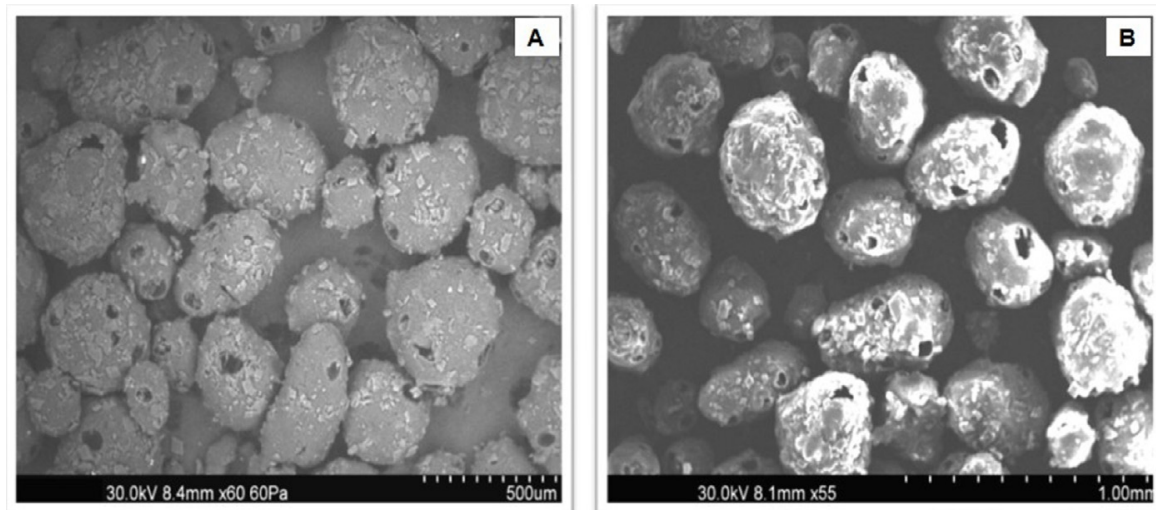

Fig. 4: Scanning electron photomicrograph: (A) at 60x magnification; (B) at 55x magnification.
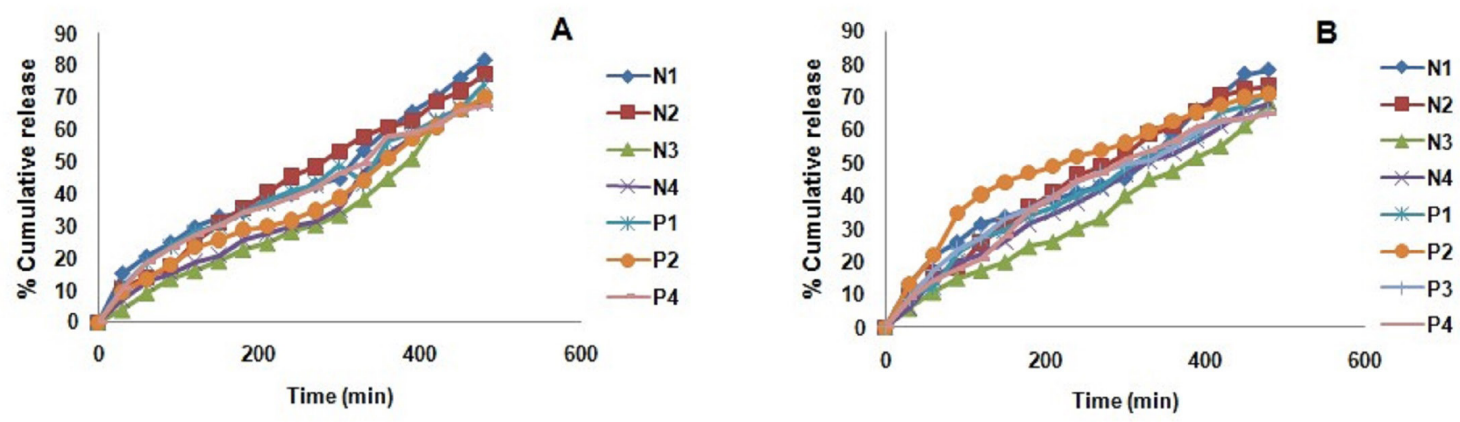

Fig. 5: Characterization of microspheres: (A) in-vitro drug release study; (B) ex-vivo permeation study.
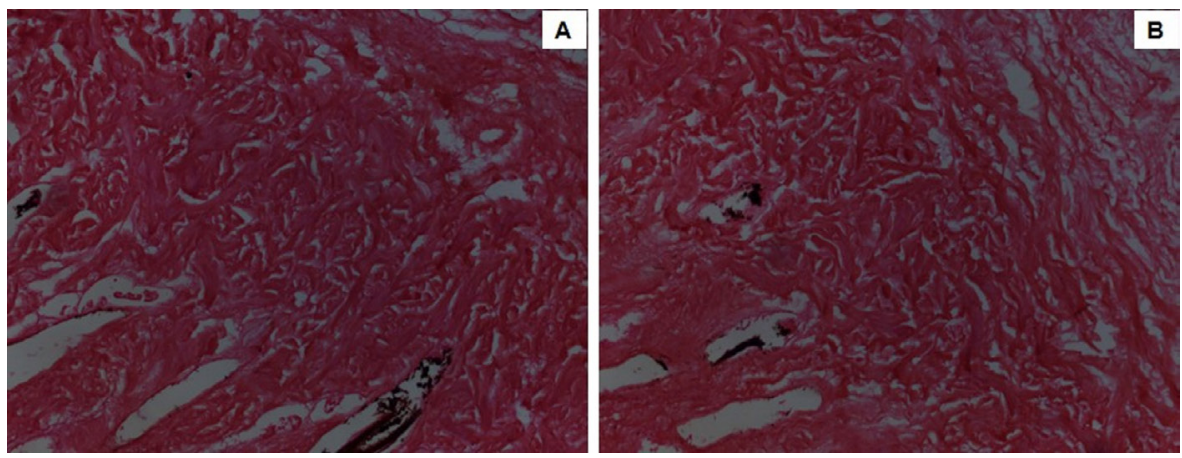

Fig. 6: Histopathological studies: (A) untreated nasal mucosa; (B) treated nasal mucosa.

\section{Ex-vivo permeation study}

The ex-vivo permeation study on sheep nasal mucosa presented the drug release profile of $\mathrm{OH}$ from the fabricated batches of carbopol 940 and HPMC K15M microspheres at pH 6.6 phosphate buffer. A noteworthy cumulative drug release was noted in the range of $64.5-78.1 \%$. The selected optimized formulation 
batch N1 presented the highest cumulative release of $78.106 \%$ as compared to other formulations (Figure 5b). The carbopol containing microspheres presented the higher cumulative release than that of HPMC based formulations. The plausible reason for better drug release of carbopol based fabricated formulations may be due to the higher molecular weight which facilitates better control release attribute (Abbas and Marihal, 2014a).

\section{Histopathological study}

After applying and examining the optimized mucoadhesive microspheres formulation on the sheep nasal mucosa after $8 \mathrm{hr}$, the histological studies displayed no harm to the nasal mucosa and no alteration in the anatomical features like cell lining and tissue were seen (Figure 6b), as compared with the untreated sheep nasal mucosa which was stained with hematoxylin-eosin (Figure 6a). This study concluded that the formulation exhibited potent mucoadhesivity with no harm to the anatomical structure.

\section{Drug release kinetics}

The analysis of in-vitro drug release data indicates that the $\mathrm{OH}$ release from the microspheres followed zero order kinetics in most of the batches like N1, N2, N3, N4, P1, and P4 as the correlation coefficient ' $\mathrm{r}$ ' values in the zero order model were higher than the other model. In contrast, only the two batches; P2 and P3 followed the Higuchi matrix of drug release. The overall kinetic study supported the diffusion mode as the primary phenomenon of drug release. The results of kinetic treatment applied to release profile of formulation N1 to P4 are shown in Table 3.

Table 3: Kinetic treatment of drug release profile of formulations.

\begin{tabular}{cccccc}
\hline \multirow{2}{*}{ Formulation } & \multicolumn{5}{c}{ Mathematical models } \\
\cline { 2 - 5 } & $\begin{array}{c}\text { Zero } \\
\text { order }\end{array}$ & $\begin{array}{c}\text { First } \\
\text { order }\end{array}$ & Higuchi & $\begin{array}{c}\text { Korsemeyer- } \\
\text { Peppas }\end{array}$ & \\
\hline N1 & 0.966 & 0.593 & 0.928 & 0.467 & Zero order \\
N2 & 0.985 & 0.657 & 0.928 & 0.482 & Zero order \\
N3 & 0.991 & 0.762 & 0.927 & 0.444 & Zero order \\
N4 & 0.991 & 0.680 & 0.962 & 0.430 & Zero order \\
P1 & 0.985 & 0.655 & 0.964 & 0.444 & Zero order \\
P2 & 0.892 & 0.498 & 0.928 & 0.388 & Higuchi \\
P3 & 0.961 & 0.601 & 0.988 & 0.402 & Higuchi \\
P4 & 0.968 & 0.664 & 0.928 & 0.442 & Zero order \\
\hline
\end{tabular}

\section{CONCLUSION}

The current research attempted at rationally formulating a mucoadhesive microparticulate system for the anti-emetic drug ondansetron $\mathrm{HCl}$ for intranasal administration with a perspective of improving the bioavailability of the drug. The research suggested that solvent evaporation remained the most relevant procedure for the fabrication of mucoadhesive microspheres of ondansetron $\mathrm{HCl}$ based on mucoadhesive polymers; carbopol 940 and HPMC $\mathrm{K} 15 \mathrm{M}$ and film forming polymer ethyl cellulose. The particle size analysis indicated that all the fabricated formulations have a particle size in the range of $15-31 \mu \mathrm{m}$ which is most convenient for the intranasal administration of the prepared formulation for enhancing bioavailability. Histopathological examination shows that the drug-loaded microsphere system had no harsh injury on the nasal mucosa. The SEM photomicrograph displayed spherical and smooth surface morphology of the formulations. From the studied parameters, it can be concluded that carbopol 940 offered better mucoadhesive attributes than HPMC K15M for the formulating $\mathrm{OH}$ intranasal mucoadhesive microspheres. Thus, the formulated microspheres could be a potential carrier for elevating the bioavailability via the intranasal route.

\section{ACKNOWLEDGMENT}

We are very grateful to thank Maxwell Life Science Private Limited, Mumbai, India for providing gift sample of ondansetron hydrochloride.

\section{ABBREVIATIONS}

OND Ondansetron Hydrochloride;

DL Drug Loading;

EE Entrapment Efficiency;

PBS Phosphate Buffer Solution;

SNF Simulated Nasal Fluid.

\section{REFERENCES}

Abbas Z, Marihal S, Akifuddin SK. Almotriptan loaded sodium alginate microspheres for nasal delivery: formulation optimization using factorial design, characterization and in-vitro evaluation. Ind J Novel Drug Deliv, 2014; 6(1):10-24.

Abbas Z, Marihal S. Gellan gum-based mucoadhesive microspheres of almotriptan for nasal administration: Formulation optimization using factorial design, characterization, and in vitro evaluation. J Pharm Bioall Sci, 2014a; 6(4):267-77.

Behl CR, Pimplaskar HK, Sileno AP, deMeireles J, Romeo VD. Effects of physicochemical properties and other factors on systemic nasal drug delivery. Adv Drug Deliv Rev, 1998; 29:89-116.

Dandge BH, Dehghan MH. Formulation and evaluation of nasal mucoadhesive microparticles of diltiazem hydrochloride. Int J ChemTech Res, 2009; 1(4):1036-1042.

Dangre PV, Godbole MD, Ingle PV, Mahapatra DK. Improved Dissolution and Bioavailability of Eprosartan Mesylate Formulated as Solid Dispersions using Conventional Methods. Indian J Pharm Edu Res, 2016; 50(3):S209-S217.

Desai S, Vidyasagar G, Shah V, Desai D. Preparation and in vitro characterisation of mucoadhesive microspheres of midazolam: nose to brain administration. Asian J Pharm Clin Res, 2011; 4(1):100-102.

Godbole MD, Mahapatra DK, Khode PD. Fabrication and Characterization of Edible Jelly Formulation of Stevioside: A Nutraceutical or OTC Aid for the Diabetic Patients. Inventi Rapid: Nutraceuticals, 2017; 2017(2):1-9.

Jain BK. Preparation and in vitro characterization of mucoadhesive Norethisterone-egg albumin microspheres for nasal administration. Asian J Biomed Pharm Sci, 2012; 2(15):49-57.

Jain SA, Chauk DS, Mahajan HS, Tekade AR, Gattani SS. Formulation and evaluation of nasal mucoadhesive microspheres of Sumatriptan succinate. J Microencapsul, 2009; 26(8):711-721.

Kashikar V, Dhole S, Kandekar U, Khose P. Study of mucoadhesive microsphere of pirfenidone for nasal drug delivery. Asian J Pharm, 2014; 8(1):46-53.

Kulkarni AD, Bari DB, Surana SJ, Pardeshi CV. In vitro, ex vivo and in vivo performance of chitosan-based spray-dried nasal mucoadhesive microspheres of diltiazem hydrochloride. J Drug Deliv Sci Tech, 2016; 31:108-117.

Mahajan HS, Tatiya BV, Nerkar PP. Ondansetron loaded pectin 
based microspheres for nasal administration: In vitro and in vivo studies. Powder Tech, 2012; 221:168-176.

Mahajan NM, Pardeshi A, Mahapatra DK, Darode A, Dumore NG. Hypromellose and Carbomer induce bioadhesion of Acyclovir tablet to vaginal mucosa. Indo Am J Pharm Res, 2017; 7(12):1108-1118.

Mahajan NM, Wadhwane P, Mahapatra DK. Rational designing of sustained release matrix formulation of Etodolac employing Hypromellose, Carbomer, Eudragit and Povidone. Int J Pharm Pharm Sci, 2017; 9(12):92-97.

Mahajan H, Gattani S, Surana S. Spray dried mucoadhesive microspheres of ondansetron for nasal administration. Int $\mathrm{J}$ Pharm Sci Nanotechnol, 2008; 1(3):267-274.

Mahapatra DK, Bharti SK. Handbook of Research in Medicinal Chemistry. Ontario, India: Apple Academic Press. 2017.

Mahapatra DK, Bharti SK. Medicinal Chemistry with Pharmaceutical Product Development. Ontario, India: Apple Academic Press. 2018.

Mahapatra DK, Bharti SK. Drug Design. New Delhi, India: Tara Publications Private Limited. 2016.

Nanjwade BK, Parikh KA, Deshmukh RV, Najwade VK, Gaikwad KR, Thakare SA, Manvi FV. Development and evaluation of intranasal mucoadhesive microspheres of neostigmine bromide. Pharm Anal Acta, 2011; 2(2):1-6.

Pagar SA, Shinkar DM, Saudagar RB. A review on intranasal drug delivery system. J Adv Pharm Edu Res, 2013; 3(4):333-346.

Pardeshi CV, Rajput PV, Belgamwar VS, Tekade AR. Formulation, optimization and evaluation of spray dried mucoadhesive microspheres as intranasal carriers for Valsartan. J Microencapsul, 2012; 29(2):103-114

Patil MD, Mahapatra DK, Dangre PV. Formulation and in-vitro evaluation of once-daily sustained release matrix tablet of nifedipine using rate retardant polymers. Inventi Rapid: Pharm Tech, 2016; 2016(4):1-7.
Pilicheva B, Zagorchev P, Uzunova Y, Kassarova M. Development and in vitro evaluation of mucoadhesive microsphere carriers for intranasal delivery of betahistine dihydrochloride. Int J Drug Dermatol, 2013; 5(3):389-401.

Prasanth VV, Chakraborty A, Mathew ST, Mathappan R, Kamalakkannan V. Formulation and evaluation of salbutamol sulphate microspheres by solvent evaporation method. J Appl Pharm Sci, 2011; 1(5):133-137.

Shahi SR, Tribhuwan SD, Tadwee IK, Gupta SK, Zadbuke NS, Shivanikar SS. Formulation of atenolol mucoadhesive microspheres for nasal delivery by spray drying technique: in vitro/ex vivo evaluation. Der Pharm Sinica, 2011; 2(5):54-63.

Sonkusre N, Dhabarde DM, Mahapatra DK. Formulation and development of mirtazapine self emulsifying drug delivery system (SEDDS) for enhancement of dissolution profile. Inventi NDDS, 2016(3):1-9.

Swamy NG, Abbas Z. Preparation and in vitro characterization of mucoadhesive hydroxypropyl guar microspheres containing amlodipine besylate for nasal administration. Indian J Pharm Sci, 2011; 73(6):608-614.

Taksande JB, Umekar MJ. Preparation of intranasal pregabalin microspheres: In vitro, ex vivo and in vivo pharmacodynamic evaluation. $\mathrm{J}$ Pharm Res, 2018; 12(1):112-121.

Umaredkar AA, Dangre PV, Mahapatra DK, Dhabarde DM. Fabrication of chitosan-alginate polyelectrolyte complexed hydrogel for controlled release of cilnidipine: a statistical design approach. Mater Technol, 2018; 1:1-11.

How to cite this article:

Dhawale P, Mahajan NM, Mahapatra DK, Mahajan UN, Gangane

PS. HPMC K15M and Carbopol 940 mediated fabrication of ondansetron hydrochloride intranasal mucoadhesive microspheres. J App Pharm Sci, 2018; 8(08): 075-083. 